\title{
Association between Health Risk Behavior and Suicidal Ideation, Continuous Sadness and Depression among Malaysian Youth
}

\author{
Nor Asiah Muhamad ${ }^{1,3}$, Norazilah Mohd Roslan², Aziman Mahdi ${ }^{2}$, Norbaidurah Ithnain², Normi Mustapha ${ }^{4}$, \\ Noor Aliza $\mathrm{L}^{1}$, Rimah Melati $\mathrm{AG}^{1}$ \& Suraiya $\mathrm{SM}^{2}$ \\ ${ }^{1}$ Institute for Public Health, Ministry of Health, Malaysia \\ ${ }^{2}$ Institute for Behavioural Health Research, Ministry of Health, Malaysia \\ ${ }^{3}$ Non Communicable Disease Section, Ministry of Health, Malaysia \\ ${ }^{4}$ Faculty of Science \& Technology, Open University Malaysia, Malaysia \\ Correspondence: Nor Asiah Muhamad, Institute for Public Health, Jalan Bangsar, Kuala Lumpur 50450, Malaysia. \\ Tel: 603-2297-9400; Fax: 603-2284-9080. E-mail: norasiahdr@gmail.com
}

Received: September 29, 2017 Accepted: October 23, 2017 Online Published: November 20, 2017

doi:10.5539/gjhs.v10n1p11

URL: https://doi.org/10.5539/gjhs.v10n1p11

\begin{abstract}
Background: Suicide is a global public health importance and a second leading cause of death in adolescents. It is more common among adolescents and is considered as a serious public health problem worldwide. This study aims to determine the association between health risk behavior with suicidal ideation, continuous sadness and depression among Malaysian youth.
\end{abstract}

Methods: A cross-sectional study was carried out among 4088 youth aged 13-17 years old from 50 selected schools. A stratified random sampling was used to select respondents from different classes. The students were randomly selected using the same software throughout the country. Verbal consent was obtained from the student and parents prior to data collection. A standardized self-administered questionnaire adapted from the United States' Youth Behaviour Risk Surveillance Survey (YBRSS) were used.

Results: The rates of Continuous Sadness (CS), Depression (DP) and Suicidal Ideation (SI) were 34.3\%, 13.2\% and $7.9 \%$ respectively. The multivariable-adjusted odds ratio showed that sexual abuse was associated with SI 8.04 (95\% CI: 4.66, 13.84), CS 5.72 (95\% CI: 3.21, 9.82) and DP 4.68\% (95\% CI: 2.80, 7.83); alcohol use was associated with SI 1.62 (95\% CI: 1.06, 2.47) and DP 1.67 (95\% CI: 1.20, 2.33). Female was associated with all suicidal behaviours: SI 2.48 (95\% CI: 1.90, 3.24), CS 2.07 (95\% CI: 1.80, 2.37) and DP 1.41 (95\% CI: 2.17, 1.71). Smoking and drug was not associated with CS, DP and SI.

Conclusions: Given the well-founded concern of increasing risk of suicidal behaviour among youth, preventive efforts should adopt a more comprehensive approach in dealing with sexual abuse and alcohol abuse, especially in female.

Keywords: suicidal ideation, continuous sadness, depression, Malaysia, youth

\section{Introduction}

Suicide is a global public health problem, which increases morbidity and mortality and impaired economic performances in a country (Serinken et al., 2008). It is more common among adolescents than other age groups (Bazrafshan et al., 2015). It is a second leading cause of death in adolescents after accidents (Kostenuik and Ratnapalan, 2010) and the third leading cause of death after accidental injuries and homicide among adolescents in the United States (Hamilton et al., 2005). Several studies have shown that suicidal behaviour in adolescents is a serious public health problem worldwide (Liu et al., 2005; Rodriguez et al., 2006; Mohammad Khani et al., 2006). According to Hawton and Van Heeringen (2009), it is currently the 10th most common cause of mortality resulting in the loss of approximately one million lives every year.

Much of the current epidemiological evidence on the incidence and prevalence of suicidal ideation and suicidal behaviours is based on the data mainly from high-income countries (Hawton \& Van Heeringen, 2009). Comparatively, very few studies on the occurrence of suicidal thoughts and behaviours are carried out in low-income countries. Previous studies suggest that the profiles of risk factors in developing countries 
demonstrate some differences from those in developed countries (Vijayakumar et al., 2005). Hence, it is possible that psycho-social and environmental factors may contribute to a larger portion of suicidal behaviours (Knipe et al., 2015).

\subsection{Health Risk Behaviour}

Health-risk behaviour can be defined as any activity undertaken by people with a frequency or intensity that increases risk of disease or injury (Adriana Baban, 2007). Substance abuse, dietary, violence and sexual behaviour are identified as health risk behaviour which lead to poor health and mental performance (Mitchell et al., 2001). Substance use in health risk behaviour including tobacco, drug and alcohol use. Violence behaviour is defined by World Health Organization (WHO) as the intentional use of physical force or power, threatened or actual, against oneself, another person, or against a group or community, which either results in or has a high likelihood of resulting in injury, death, psychological harm, maldevelopment, or deprivation. Sexual abuse is also considered as violence behaviour. Risky sexual behaviour includes having multiple partners and not using condom (Shrier, Harris, Sternberg, \& Beardslee, 2001).

\subsection{Suicide Screening and Prevention}

Suicidal ideation among adolescents is associated with several psychosocial indicators for well-being including: depression (Cash \& Bridge, 2009), loneliness (Rudatsikira et al., 2007), anxiety (Cash \& Bridge, 2009), substance use (Cash \& Bridge, 2009; Muula et al., 2007), poverty (Burrows \& Laflamme, 2008; Christiansen et al., 2011), bullying (Owusu et al., 2011), poor relationship quality with parents (Bridge et al., 2006), and low social support (King \& Merchant, 2008). Girls are more likely to engage in suicidal ideations, planning, and attempts whereas boys are more likely to complete a suicide (Foley et al., 2006). Suicide prevention programs is used to screen signs of suicidal behaviour for early intervention. It is important to understand the risk factors for suicidal behaviour as well as identifying a method for screening and prevention (Nock et al., 2008). Suicidal behaviour also is greatly increased with the presence of both depression and an anxiety.

\subsection{Suicidal Ideation, Continuous Sadness and Depression}

Suicidal ideation is defined as thoughts, ideas and the desire to commit suicide (Ying et al., 2016). It is a developmental transition that occur due to changes in family relationships, peer pressure, and increased opportunities for alcohol and drug use (Brent et al., 2002; Runeson \& Asberg, 2003). Disruption or absent of social support from family and friends will lead to suicide ideation among adolescents, adults, and college students (Harris \& Molock, 2000; Marion \& Range, 2003; Prinstein et al., 2000; Stravynski \& Boyer, 2001). It is also associated with poor psychosocial functioning, risky sexual behaviour and aggressive behaviour (Reinherz et al., 2006). Continuous sadness is social disconnection and isolation or feeling of helplessness that might be critical influences on suicidal behaviour (Joiner, 2005). Depression is also one of significant characteristic that contribute to suicidal ideation (Brown et al., 2000; Sokero et al., 2005).

Therefore this present study aimed to investigate the association between health risk behaviour with suicidal ideation, continuous sadness and depression among Malaysian youth.

\section{Material and Methods}

\subsection{Study Design and Sampling}

A cross-sectional multi-centre study was conducted from September to December 2010. A total of 5000 questionnaires were distributed among the respondents age 13-17. Of these, 4088 respondents answered the questionnaire giving rise to $81.8 \%$ response rate. The respondents were equally proportionate among the school type, gender and age. The respondents were interviewed from 50 selected secondary schools across Malaysia.The schools were randomized by using Statistical Package for the Social Sciences (SPSS Inc. Chicago, IL, USA) software based on a multi-level selection. The students were randomly selected using the same software throughout the country. Verbal consent was obtained from the student and parents prior to data collection. Participant who were absent, have literacy issues and who refused to participate were excluded from the study. Ethical approval was obtained from Medical Research and Ethics Committee (MREC) Ministry of Health, Malaysia.

\subsection{Data Collection}

The study instrument was a standardized self-administered questionnaire which was adapted from the United States' Youth Behaviour Risk Surveillance Survey (YBRSS) and translated back to back to Malay language. The translation was carried out by technical expert in their field assisted by an expert group in English and Malay language. The translated questionnaire was further examined by certified English translator. The Malay version 
questionnaire was pre tested to a group of youth with the Cronbach alpha 0.82 . The questionnaire contained two domains namely socio demography and health risk behaviour assessment for Malaysian youth. The questionnaire was distributed among the respondents in different sessions according to the age group. Researchers minimally explained to the respondents the method of answering the questionnaire prior to the distribution of the questionnaire.

\subsection{Statistical Analysis}

Data were analysed using SPSS software version 21.0. Basic characteristics were described using descriptive statistics. Association of the variables were identified by univariable analyses. In the final model, risk factors were determined by performing multiple logistic regressions. Significant association was based on $p<0.05$.

\section{Results}

Table 1 shows that most of the respondents were Malays (66.2\%) compared to other ethnicities. Those who used alcohol were $6.3 \%$, drug $0.6 \%$, smoking $8.9 \%$ and $1.6 \%$ has history of sexual abuse. The rates of continuous sadness (CS), depression (DP) and suicidal ideation (SI) in this sample were $34.3 \%, 13.2 \%$ and $7.9 \%$, respectively.

Table 1. Socio-demographic characteristics and health risk behaviours among study subjects

\begin{tabular}{|c|c|}
\hline \multirow{2}{*}{ Characteristic } & All Subjects \\
\hline & $\mathrm{N}$ (\% of characteristic) \\
\hline Age, mean (SD) & $14.27(1.22)$ \\
\hline \multicolumn{2}{|l|}{ Gender } \\
\hline Female & $2267(55 \%)$ \\
\hline Male & $1811(45 \%)$ \\
\hline \multicolumn{2}{|l|}{ Ethnicity } \\
\hline Malay & $2582(66.2 \%)$ \\
\hline Chinese & $773(16.9 \%)$ \\
\hline Indian & $200(5.3 \%)$ \\
\hline Bumiputra Sarawak & $194(4.6 \%)$ \\
\hline Others & $39(1.1 \%)$ \\
\hline Orang Asli & $10(0.3 \%)$ \\
\hline \multicolumn{2}{|l|}{ Religion } \\
\hline Islam & $2810(71.3 \%)$ \\
\hline Buddhist & $665(14.6 \%)$ \\
\hline Christianity & $406(9.2 \%)$ \\
\hline Hinduism & $174(4.6 \%)$ \\
\hline Others & $7(0.2 \%)$ \\
\hline Atheist & $5(0.1 \%)$ \\
\hline \multicolumn{2}{|l|}{ Substance use } \\
\hline \multicolumn{2}{|l|}{ Alcohol } \\
\hline Yes & $256(6.3 \%)$ \\
\hline No & $3829(93.7 \%)$ \\
\hline \multicolumn{2}{|c|}{ History of sexual abuse } \\
\hline Yes & $64(1.6 \%)$ \\
\hline No & $4016(98.2 \%)$ \\
\hline \multicolumn{2}{|l|}{ Smoking } \\
\hline Yes & $362(8.9 \%)$ \\
\hline
\end{tabular}


No

Drug abuse

Yes

No

Depression (DP)

Yes

No

Continuous Sadness (CS)

Yes

No

Suicidal Ideation (CI)

Yes

No
$3724(91.1 \%)$

$25(0.6 \%)$

$4056(99.3 \%)$

$532(13.2 \%)$

3537 (86.8\%)

1398 (34.3\%)

2653 (65.7\%)

$313(7.9 \%)$

3762 (92.1\%)

Table 2 shows the sexual abuse was significantly associated with suicidal ideation (SI) 8.04 (95\% CI: 4.66, 13.84), continuous sadness (CS) 5.72 (95\% CI: 3.21, 9.82) and depression (DP) 4.68\% (95\% CI: 2.80, 7.83); alcohol abuse was associated with SI 1.62 (95\% CI: 1.06, 2.47) and DP 1.67 (95\% CI: 1.20, 2.33). Female was associated with all suicidal behaviours: SI 2.48 (95\% CI: 1.90, 3.24), CS 2.07 (95\% CI: 1.80, 2.37) and DP 1.41 (95\% CI: 2.17, 1.71).

Table 2. Risk factors for suicidal ideation, continuous sadness and depression among Malaysian youth

\begin{tabular}{llllllll}
\hline & Factors & B & S.E. & Wald & P-value & Adjusted OR* & 95\%CI \\
\hline Suicidal Ideation & Female gender & 0.91 & .135 & 45.13 & $<0.001$ & 2.48 & $1.90,3.24$ \\
& History of sexual abuse & 2.08 & 0.28 & 56.37 & $<0.001$ & 8.04 & $4.66,13.84$ \\
& Alcohol & 0.48 & 0.22 & 4.93 & 0.026 & 1.62 & $1.06,2.47$ \\
Continuous Sadness & Female gender & 0.73 & .07 & 108.94 & $<0.001$ & 2.07 & $180,2.37$ \\
& History of sexual abuse & 1.54 & 0.26 & 36.67 & $<0.001$ & 5.72 & $3.21,9.82$ \\
Depression & Female gender & 0.34 & 0.11 & 12.60 & $<0.001$ & 1.41 & $2.17,1.71$ \\
& History of sexual abuse & 1.54 & 0.26 & 36.67 & $<0.001$ & 5.72 & $3.21,9.82$ \\
\hline
\end{tabular}

\section{Discussion}

This study found that sexual abuse was associated with SI, CS and DP. This finding is similar with a study done by Arria et al., (2010) and Chan et al., (2013). Adolescents belonging to age group 13 to 17 years old with a history of sexual abuse were more likely to experience SI (56.37), CS (36.67) and DP (34.66).

History of sexual abuse among adolescent age 13 to 17 years old was $1.6 \%(n=4088)$. Study by Chan et al., (2013) showed that history of sexual abuse increased exponentially with age among Malaysian adolescents. Another study by S. Maria et al., (2010) showed respondents age 18 to 24 years old had history of sexual abuse. Lee et al., (2006) also showed that secondary school students have experienced sexual intercourse between age 12 to 19. Childhood sexual abuse will increase the possibilities of having mental disorders including depression and suicidal ideation.

In this study, percentage of alcohol abuse, $6.3 \%$ is lower as compared to S. Maria et al., (2010), which is $8.7 \%$ and Chan et al., (2013), 24.8\%. Alcohol abuse was associated with DP and SI but not with CS. Study by Sabate (2004) demonstrated the commonest signs and symptoms of depression were suicidal thoughts, hopelessness, social isolation, drug or alcohol abuse, overeating and oversleeping, and rage among adolescents age between 12 and 18 . Peter T et al., (2008) found it was important to remember that depressive symptoms and substance abuse were the strongest predictors of suicidal ideation.

This study also showed that young females were more likely to be at risk in SI, CS and DP. This is similar to the 
study done by Beautrais (2002), which showed that young females were twice as likely as males to report suicidal ideation and suicide attempt behaviour.

Spirito (2006) stated that suicide was the third leading cause of death in adolescence, and medically serious suicide attempts occurred in approximately 3\% of adolescents. This review examined a number of risk factors that contributed to suicidal behaviour. A prior suicide attempt was one of the best predictors of both a repeat attempt and eventual completed suicide.

\section{Conclusion}

This paper provided a basis for placing emphasis on factors that could be associated with health risk behavior and suicidal ideation, continuous sadness and depression. Health risk behavior plays a major role in increasing depression, continuous sadness and suicidal ideation. Suicide prevention should be carried out with early detection of identified risk factors and appropriate intervention. Further identification and preventive efforts should adopt a more comprehensive approach in the future will help to elucidate this area, and contribute to the development strategies for youth and adolescents, especially in female. Social element of suicide consists of socio-demographic, social-environmental, and social-psychological factors that associate many youths into suicidal ideation should be taken into consideration (Pletzer, 2012).

\section{Acknowledgements}

We would like to thank the Director General of Health Malaysia for permission to publish this paper. We would also like to express our gratitude to the Deputy Director General of Health (Research and Technical Support) for her technical advice and continuous support. Lastly, we would also thank all participants for their contribution and assistance.

\section{Competing Interests Statement}

The authors declare that there are no competing or potential conflicts of interest.

\section{References}

Adriana, B., \& Catrinel, C. (2007). Jebp. Changing Health-Risk Behaviors: A Review of Theory and Evidence-Based Interventions In Health Psychology. pp 45-67.

Arria, A. M., O'Grady, K. E., Caldeira, K. M., Vincent, K. B., Wilcox, H. C., \& Wish, E. D. (2009). Suicide ideation among college students: A multivariate analysis. Archives of Suicide Research, 13(3), 230-246.

Awaluddin, S. M., Ahmad, N. A., Saleh, N. M., Aris, T., Kasim, N. M., Sapri, N. A. M., \& Rashid, N. R. N. A. (2015). Prevalence of sexual activity in older Malaysian adolescents and associated factors. Journal of Public Health Aspects, 2(1), 1. https://doi.org/10.7243/2055-7205-2-1

Baban, A., \& Craciun, C. (2007). Changing health-risk behaviors: A review of theory and evidence-based interventions in health psychology. Journal of Cognitive \& Behavioral Psychotherapies, 7(1).

Bazrafshan, M. R., Sharif, F., Molazem, Z., \& Mani, A. (2015). Cultural concepts and themes of suicidal attempt among Iranian adolescents. International journal of high risk behaviors \& addiction, 4(1), e22589. https://doi.org/10.5812/ijhrba.22589

Beautrais, A. L. (2002). Gender issues in youth suicidal behaviour. Emergency Medicine Australasia, 14(1), 35-42. https://doi.org/10.1046/j.1442-2026.2002.00283.x

Brent, D. A., Oquendo, M., Birmaher, B., Greenhill, L., Kolko, D., Stanley, B., ... \& Salazar, J. O. (2002). Familial pathways to early-onset suicide attempt: risk for suicidal behavior in offspring of mood-disordered suicide attempters. Archives of general psychiatry, 59(9), 801-807. https://doi.org/10.1001/archpsyc.59.9.801

Bridge, J. A., Goldstein, T. R., \& Brent, D. A. (2006). Adolescent suicide and suicidal behavior. Journal of child psychology and psychiatry, 47(3 - 4), 372-394. https://doi.org/10.1111/j.1469-7610.2006.01615.x

Brown, G. K., Beck, A. T., Steer, R. A., \& Grisham, J. R. (2000). Risk factors for suicide in psychiatric outpatients: a 20-year prospective study. Journal of consulting and clinical psychology, 68(3), 371. https://doi.org/10.1037/0022-006X.68.3.371

Burrows, S., \& Laflamme, L. (2008). Suicide among urban South African adolescents. International journal of adolescent medicine and health, 20(4), 519-528. https://doi.org/10.1515/IJAMH.2008.20.4.519

Cash, S. J., \& Bridge, J. A. (2009). Epidemiology of youth suicide and suicidal behavior. Current opinion in pediatrics, 21(5), 613. https://doi.org/10.1097/MOP.0b013e32833063e1 
Chan, L. F., Maniam, T., Saini, S. M., Shah, S. A., Loh, S. F., Sinniah, A., ... \& Tan, S. M. K. (2013). Sexual abuse and substance abuse increase risk of suicidal behavior in Malaysian youth. Asia - Pacific Psychiatry, 5(S1), 123-126. https://doi.org/10.1111/appy.12057

Chan, Y. Y., Lim, K. H., Teh, C. H., Kee, C. C., Ghazali, S. M., Lim, K. K., ... \& Ibrahim, N. (2016). Prevalence and risk factors associated with suicidal ideation among adolescents in Malaysia. International journal of adolescent medicine and health. https://doi.org/10.1515/ijamh-2016-0053

Christiansen, E., Goldney, R. D., Beautrai, A. L., \& Agerbo, E. (2011). Youth suicide attempts and the doseresponse relationship to parental risk factors: A population-based study. Psychological medicine, 41(2), 313-319. https://doi.org/10.1017/S0033291710000747

Foley, D. L., Goldston, D. B., Costello, E. J., \& Angold, A. (2006). Proximal psychiatric risk factors for suicidality in youth: the Great Smoky Mountains Study. Archives of general psychiatry, 63(9), 1017-1024. https://doi.org/10.1001/archpsyc.63.9.1017

Hamilton, B. E., Miniño, A. M., Martin, J. A., Kochanek, K. D., Strobino, D. M., \& Guyer, B. (2007). Annual summary of vital statistics: 2005. Pediatrics, 119(2), 345-360.

Harris, T. L., \& Molock, S. D. (2000). Cultural orientation, family cohesion, and family support in suicide ideation and depression among African American college students. Suicide and Life-Threatening Behavior, 30(4), 341-353.

Hawton, K., \& Van Heeringen, K. (2009). Suicide. The Lancet, 373, 1372-1381. https://doi.org/10.1016/S0140-6736(09)60372-X

Joiner, T. (2007). Why people die by suicide. Harvard University Press.

King, C. A., \& Merchant, C. R. (2008). Social and interpersonal factors relating to adolescent suicidality: A review of the literature. Archives of Suicide Research, 12(3), 181-196.

Knipe, D. W., Carroll, R., Thomas, K. H., Pease, A., Gunnell, D., \& Metcalfe, C. (2015). Association of socio-economic position and suicide/attempted suicide in low and middle income countries in South and South-East Asia-a systematic review. BMC public health, 15(1), 1055. https://doi.org/10.1186/s12889-015-2301-5

Kostenuik, M., \& Ratnapalan, M. (2010). Approach to adolescent suicide prevention. Canadian family physician, 56(8), 755-760.

Lee, L. K., Chen, P. C., Lee, K. K., \& Kaur, J. (2006). Premarital sexual intercourse among adolescents in Malaysia: a cross-sectional Malaysian school survey. Singapore medical journal, 47(6), 476-481.

Liu, X., Tein, J. Y., Zhao, Z., \& Sandler, I. N. (2005). Suicidality and correlates among rural adolescents of China. Journal of Adolescent Health, 37(6), 443-451. https://doi.org/10.1016/j.jadohealth.2004.08.027

Marion, M. S., \& Range, L. M. (2003). African American college women's suicide buffers. Suicide and Life-Threatening Behavior, 33(1), 33-43. https://doi.org/10.1521/suli.33.1.33.22780

Mireault, M., \& de Man, A. F. (1996). Suicidal ideation among the elderly: Personal variables, stress and social support. Social Behavior and Personality: an international journal, 24(4), 385-392. https://doi.org/10.2224/sbp.1996.24.4.385

Mohammadkhani, P., Mohammadi, M. R., Delavar, A., Khushabi, K. S., Rezaei Dogaheh, E., \& Azadmehr, H. (2006). Predisposing and precipitating risk factors for suicide ideations and suicide attempts in young and adolescent girls. Medical Journal of The Islamic Republic of Iran (MJIRI), 20(3), 123-129.

Muula, A. S., Kazembe, L. N., Rudatsikira, E., \& Siziya, S. (2007). Suicidal ideation and associated factors among in-school adolescents in Zambia. Tanzania Journal of Health Research, 9(3), 202-206.

Nock, M. K., Borges, G., Bromet, E. J., Alonso, J., Angermeyer, M., Beautrais, A., ... \& De Graaf, R. (2008). Cross-national prevalence and risk factors for suicidal ideation, plans and attempts. The British Journal of Psychiatry, 192(2), 98-105. https://doi.org/10.1192/bjp.bp.107.040113

Owusu, A., Hart, P., Oliver, B., \& Kang, M. (2011). The association between bullying and psychological health among senior high school students in Ghana, West Africa. Journal of School Health, 81(5), 231-238. https://doi.org/10.1111/j.1746-1561.2011.00590.x

Peltzer, K., \& Pengpid, S. (2012). Suicidal ideation and associated factors among school-going adolescents in Thailand. International journal of environmental research and public health, 9(2), 462-473. 
https://doi.org/10.3390/ijerph9020462

Peter, T., Roberts, L. W., \& Buzdugan, R. (2008). Suicidal ideation among Canadian youth: A multivariate analysis. Archives of Suicide Research, 12(3), 263-275. https://doi.org/10.1080/13811110802100882

Prinstein, M. J., Boergers, J., \& Spirito, A. (2001). Adolescents' and their friends' health-risk behavior: Factors that alter or add to peer influence. Journal of pediatric psychology, 26(5), 287-298.

Prinstein, M. J., Boergers, J., Spirito, A., Little, T. D., \& Grapentine, W. L. (2000). Peer functioning, family dysfunction, and psychological symptoms in a risk factor model for adolescent inpatients' suicidal ideation $\begin{array}{lllll}\text { severity. Journal of Clinical } & \text { Child Psychology, 29(3), }\end{array}$ https://doi.org/10.1207/S15374424JCCP2903_10

Reinherz, H. Z., Tanner, J. L., Berger, S. R., Beardslee, W. R., \& Fitzmaurice, G. M. (2006). Adolescent suicidal ideation as predictive of psychopathology, suicidal behavior, and compromised functioning at age 30 . American Journal of Psychiatry, 163(7), 1226-1232. https://doi.org/10.1176/ajp.2006.163.7.1226

Rodríguez, A. H., Caldera, T., Kullgren, G., \& Renberg, E. S. (2006). Suicidal expressions among young people in Nicaragua. Social psychiatry and psychiatric epidemiology, 41(9), $692-697$. https://doi.org/10.1007/s00127-006-0083-x

Rudatsikira, E., Muula, A. S., Siziya, S., \& Twa-Twa, J. (2007). Suicidal ideation and associated factors among $\begin{array}{llllll}\text { school-going adolescents in rural Uganda. BMC psychiatry, } & 7(1), & 67 .\end{array}$ https://doi.org/10.1186/1471-244X-7-67

Runeson, B., \& Åsberg, M. (2003). Family history of suicide among suicide victims. American Journal of Psychiatry, 160(8), 1525-1526. https://doi.org/10.1176/appi.ajp.160.8.1525

Sabaté, E. (2004). Depression in young people and the elderly. Priority medicines for Europe and the world " $A$ public health approach to innovation". WHO, 6.

Serinken, M., Karcioglu, O., Sengul, C., Turkcuer, I., \& Keysan, M. K. (2008). Hospital costs of managing deliberate self-poisoning in Turkey. Medical science monitor, 14(3), CR152-CR158.

Shrier, L. A., Harris, S. K., Sternberg, M., \& Beardslee, W. R. (2001). Associations of depression, self-esteem, and substance use with sexual risk among adolescents. Preventive medicine, 33(3), 179-189.

Sokero, T. P., Melartin, T. K., Rytsälä, H. J., Leskelä, U. S., Lestelä-Mielonen, P. S., \& Isometsä, E. T. (2005). Prospective study of risk factors for attempted suicide among patients with DSM-IV major depressive disorder. The British Journal of Psychiatry, 186(4), 314-318. https://doi.org/10.1192/bjp.186.4.314

Spirito, A., \& Esposito-Smythers, C. (2006). Attempted and completed suicide in adolescence. Annu. Rev. Clin. Psychol., 2, 237-266. https://doi.org/10.1146/annurev.clinpsy.2.022305.095323

Stravynski, A., \& Boyer, R. (2001). Loneliness in relation to suicide ideation and parasuicide: a population-wide study. Suicide and Life-Threatening Behavior, 31(1), 32-40. https://doi.org/10.1521/suli.31.1.32.21312

US Food and Drug Administration.2007. Antidepressant use in children, adolescents, and adults. [Accessed Sep 20, 2015].

Vijayakumar, L., John, S., Pirkis, J., \& Whiteford, H. (2005). Suicide in developing countries (2): risk factors. Crisis: The Journal of Crisis Intervention and Suicide Prevention, 26(3), 112. https://doi.org/10.1027/0227-5910.26.3.112

Young, S. E., Corley, R. P., Stallings, M. C., Rhee, S. H., Crowley, T. J., \& Hewitt, J. K. (2002). Substance use, abuse and dependence in adolescence: prevalence, symptom profiles and correlates. Drug and alcohol dependence, 68(3), 309-322.

\section{Copyrights}

Copyright for this article is retained by the author(s), with first publication rights granted to the journal.

This is an open-access article distributed under the terms and conditions of the Creative Commons Attribution license (http://creativecommons.org/licenses/by/4.0/). 